and recurrent aortic insufficiency $(>2+)$ at 3 years was $100 \%$ in the plication-only group and $94 \% \pm 6 \%$ and $89 \% \pm$ $11 \%$ in the plication with resuspension group.

\section{DISCUSSION}

Free margin plication is an effective technique for the correction of cusp prolapse and can be performed in a simple and systematic manner with stable midterm results. It is ideally used in the presence of good-quality cusp tissue and can be used in conjunction with free margin resuspension.

\section{References}

1. Boodhwani M, de Kerchove L, Glineur D, Poncelet A, Rubay J, Astarci P, et al Repair-oriented classification of aortic insufficiency: Impact on surgical techniques and clinical outcomes. J Thorac Cardiovasc Surg. 2009;137:286-94.

2. Aicher D, Langer F, Adam O, Tscholl D, Lausberg H, Schafers HJ. Cusp repair in aortic valve reconstruction: does the technique affect stability? $J$ Thorac Cardiovasc Surg. 2007; 134:1533-9.

3. David TE, Armstrong S, Ivanov J, Webb GD. Aortic valve sparing operations: an update. Ann Thorac Surg. 1999;67:1840-2, 1853-6.

4. El Khoury G, Vanoverschelde JL, Glineur D, Poncelet A, Verhelst R, Astarci P, et al. Repair of aortic valve prolapse: experience with 44 patients. Eur J Cardiothorac Surg. 2004;26:628-33.

5. Schafers HJ, Bierbach B, Aicher D. A new approach to the assessment of aortic cusp geometry. J Thorac Cardiovasc Surg. 2006;132:436-8.

\title{
The incorporated aortomitral homograft: A new surgical option for double valve endocarditis
}

\author{
Jose L. Navia, MD, FACC, Sharif Al-Ruzzeh, PhD, FRCS, Steven Gordon, MD, Thomas Fraser, MD, \\ Oscar Agüero, MD, and Leonardo Rodríguez, MD, Cleveland, Ohio
}

The repair or reconstruction of a disrupted aortomitral curtain or intervalvular fibrous body (IFB), as a result of extensive endocarditis with abscess formation or of reoperation, is a challenge to the cardiac surgeon. ${ }^{1}$ In this report, we describe a new surgical technique for repair or reconstruction of the IFB in the setting of double valve endocarditis involving the aortic valve (AV), the mitral valve (MV) and IFB.

\section{CLINICAL SUMMARY}

A 57-year-old man was admitted electively after two episodes of MV and AV viridans streptococcal endocarditis. The patient was treated with antibiotics, and eventually grade 3 to 4 aortic regurgitation and grade 3 to 4 mitral regurgitation developed, as did paroxysmal atrial fibrillation. A combined procedure of bipolar radiofrequency ablation for atrial fibrillation as well as a new technique of aortomitral homograft as a single unit were discussed with the patient, who agreed to proceed and signed the informed consent form. This new technique was approved by the Institutional Review Board and Innovation Practice Committee of the Cleveland Clinic Foundation.

From the Cleveland Clinic, Cleveland, Ohio.

Disclosures: J.L.N. serves as a consultant to Cryolife Inc, Kennesaw, Ga.

Received for publication May 1, 2009; accepted for publication May 17, 2009; available ahead of print July 13, 2009.

Address for reprints: Jose L. Navia MD, FACC, Cleveland Clinic, 9500 Euclid Ave, Cleveland, OH 44195.

J Thorac Cardiovasc Surg 2010;139:1077-81

$0022-5223 / \$ 36.00$

Copyright (c) 2010 by The American Association for Thoracic Surgery

doi:10.1016/j.jtcvs.2009.05.017

\section{HOMOGRAFT PREPARATION}

The aortomitral homograft was prepared by Cryolife Inc (Kennesaw, Ga). It was harvested as a single unit by opening the left atrium, preserving the dome at the level of the aortic root. The MV annulus, leaflets, and subvalvular apparatus were anatomically evaluated, and the valve, anterior, and posterior leaflet heights were measured. The distal ascending aorta was then transected, and the AV, coronary ostia, and the ascending aorta were anatomically evaluated and measured. Then the left ventricle was opened below the papillary muscle level, and the whole MV was excised or removed by incision of the valve circumferentially. The incision was placed near the fibrous annulus of the valve and around the posterior area of the annulus, preserving the aortomitral membrane, the ascending aorta, the dome of the left atrium at the reflection of the aortic root, and the MV annulus intact as a single unit (Figure 1).

\section{PREOPERATIVE ECHOCARDIOGRAPHY}

An echocardiographic examination performed about a month before the operation showed severe grade 3 to 4 aortic regurgitation, with vegetations on the right and noncoronary cusps floating into the left ventricle and the aorta. This was seen as a linear echodensity $(0.5 \times 0.3 \mathrm{~cm})$ on the ventricular side of the $\mathrm{AV}$, consistent with a vegetation (Figure 2). It also showed severe grade 3 to 4 mitral regurgitation, posteriorly directed flow, and severe eccentric multiple shunts, as well as some potential perforation of the anterior leaflet of the MV. The multiple eccentric jets indicated involvement of the IFB, most probably by abscess and vegetation formation. There was a bright calcific 


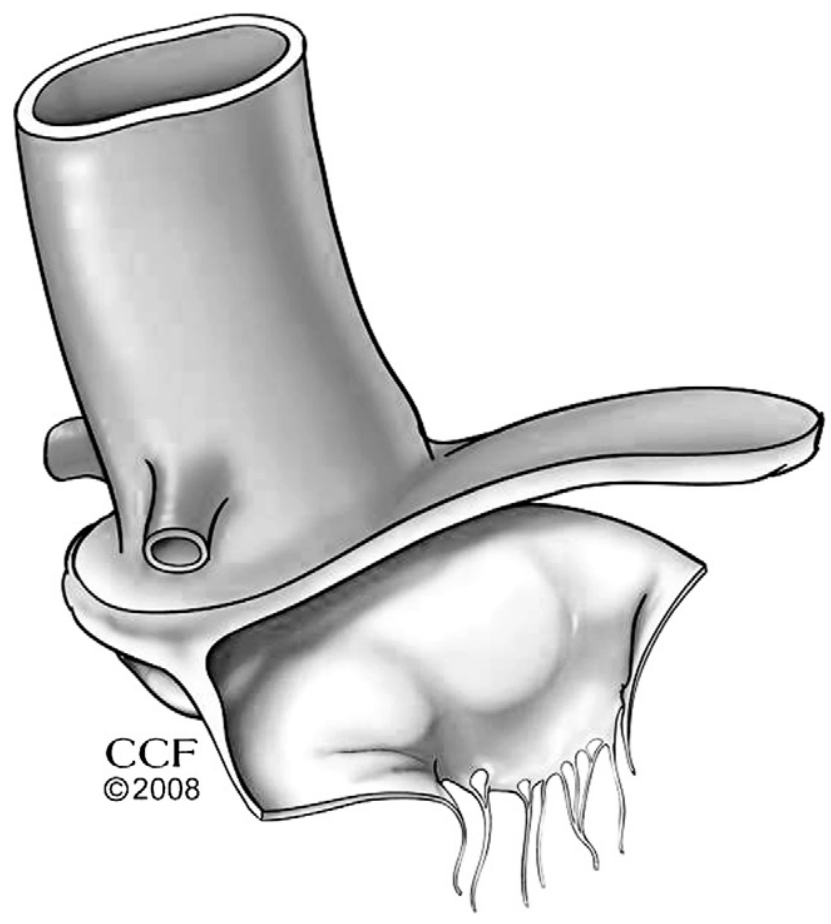

FIGURE 1. Harvested aortomitral homograft.

echodensity seen on the anterior MV leaflet, consistent with large vegetations. The left ventricular size and systolic function were normal, with an estimated ejection fraction of $60 \%$ and stage 1 diastolic dysfunction. Cardiac catheterization revealed normal coronary arteries.

\section{OPERATION}

After median sternotomy, the pericardium was opened in the midline and reflected laterally. The patient was fully hep-

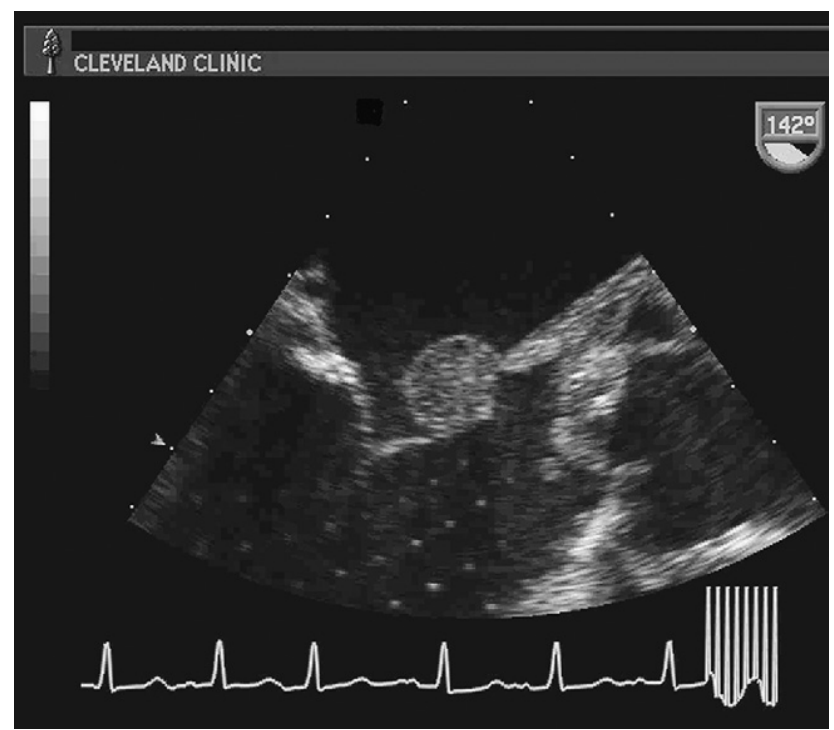

FIGURE 2. Preoperative transesophageal echocardiogram showing vegetation and thickening on anterior mitral valve leaflet.

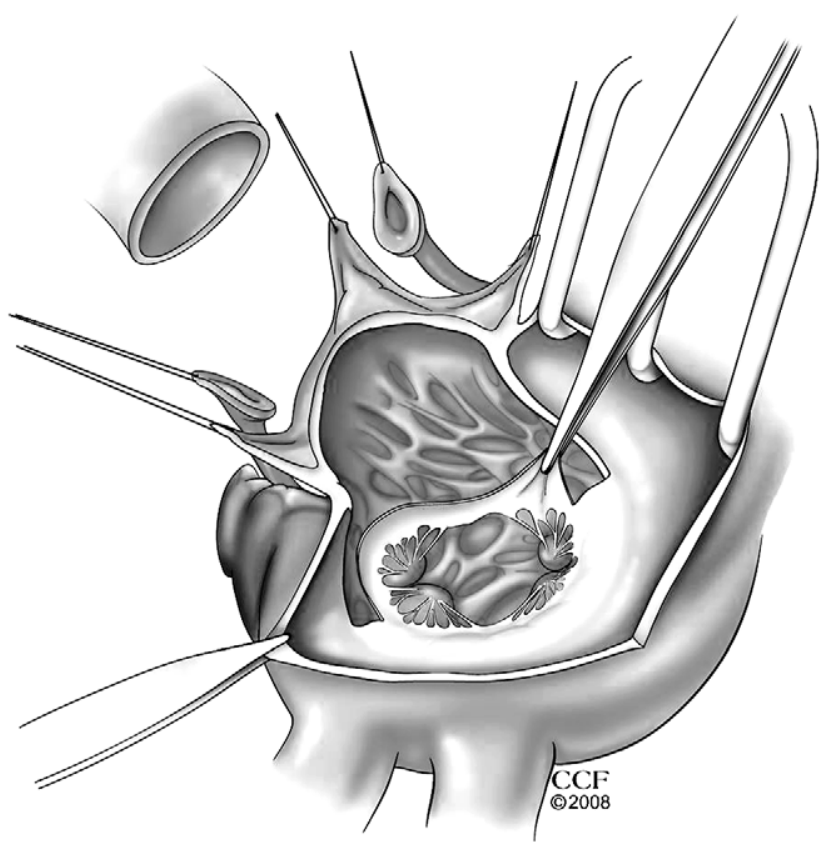

FIGURE 3. Surgeon's view of heart after complete removal of infected tissue.

arinized. The distal ascending aorta below the brachiocephalic artery was cannulated, as were the superior and inferior venae cavae. Once the activated clotting time was more than 500 seconds, cardiopulmonary bypass was instituted and the ascending aorta was crossclamped. Myocardial protection was induced by cold antegrade blood cardioplegia and maintained by intermittent administration of retrograde blood cardioplegia through the coronary sinus. Pulmonary vein isolations were performed with the bipolar radiofrequency Cardioblate device (Medtronic, Inc, Minneapolis, Minn). The ascending aorta was opened about $1 \mathrm{~cm}$ above the aortic sinus and completely transected. The three AV leaflets were completely excised, and the coronary ostia were prepared as buttons as in the Bentall procedure. The right atrium was opened to approach the MV through the interatrial septum. The MV was structurally normal but with extremely thickened anterior leaflet and multiple perforations at the level of the IBF as a result of a healing process and with many vegetations on the atrial surface. In this case, the posterior MV leaflet was confirmed to be free of severe disease. Most of the anterior leaflet was resected, leaving only the free edge, where the first and second chordae were attached to the leaflet (the rough zone; Figure 3). The intertrigonal distance and the height of the anterior MV leaflet were measured with the MV ring sizers before resection to maintain the same distance between the IFB and rough zone, the height of the anterior leaflet. Obviously, this was essential to preserve normal mobility and avoid excessive tissue that could have caused prolapse or deficient tissue 


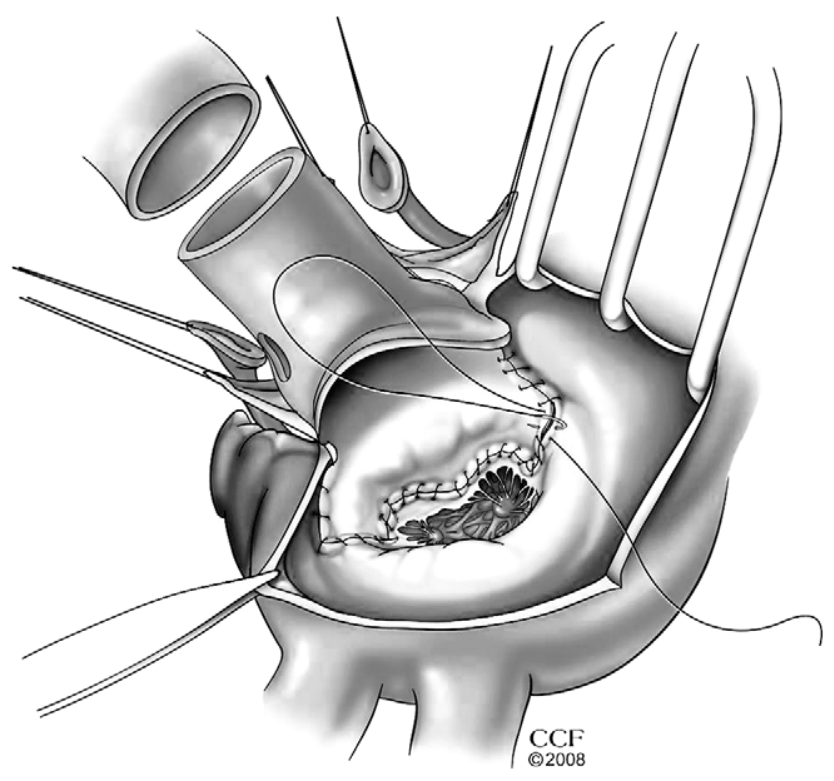

FIGURE 4. Implantation of aortomitral homograft.

that could have caused restrictive regurgitation. In the complete homograft, the same concept was strictly followed with the anterior MV leaflet. The intertrigonal distance and the height of the MV leaflet were also measured, not only for the reason previously mentioned but also to decide on the ring size required for the annuloplasty. The trimmed anterior leaflet of the homograft was sutured to the free edge of the native MV anterior leaflet, and the remains of the native trigone were sutured to the homograft trigone. Annuloplasty stitches were placed around the posterior annulus from trigone to trigone to place a $34-\mathrm{mm}$ Cosgrove-

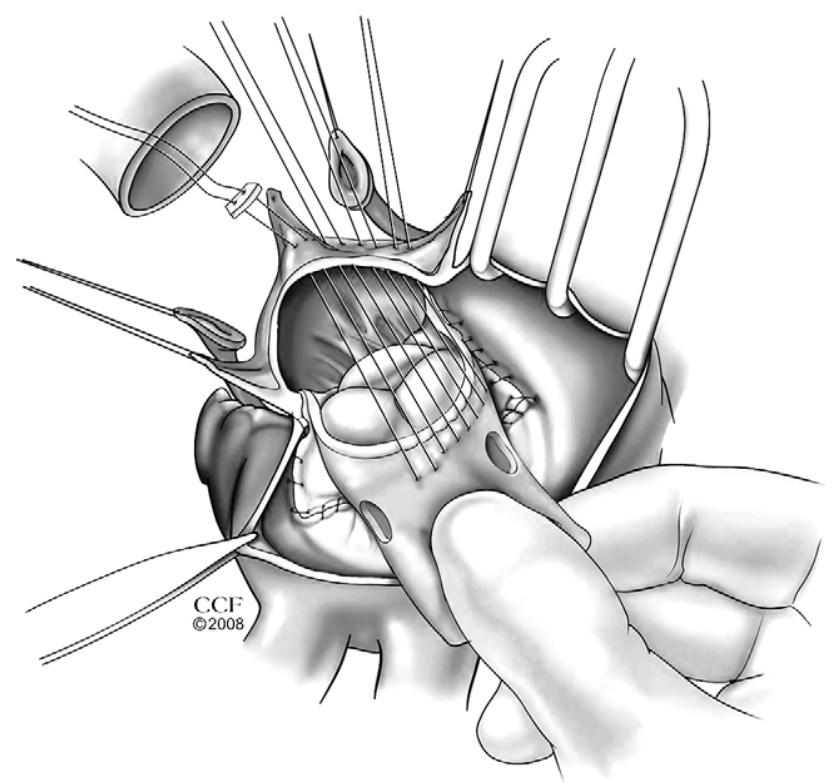

FIGURE 5. Implantation of aortomitral homograft.

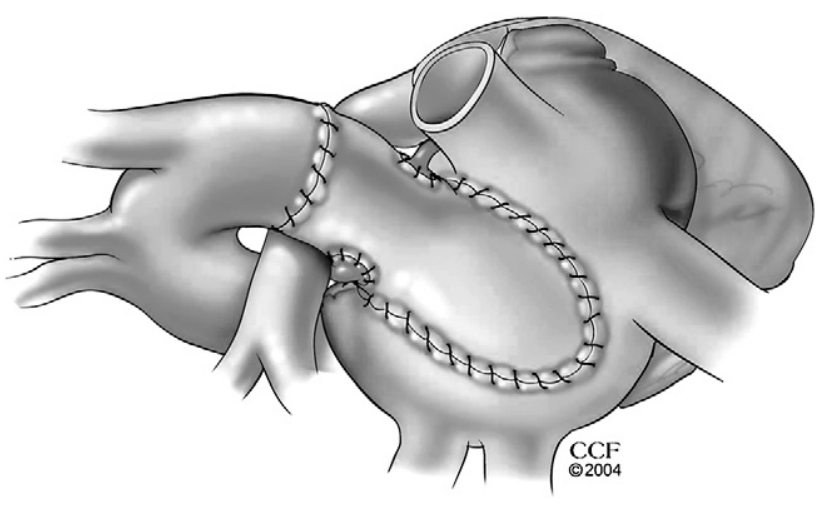

FIGURE 6. Implantation of aortomitral homograft.

Edwards ring (Edwards Lifesciences LLC, Irvine, Calif). The proximal end of the aortic part of the homograft was sutured to the native aortic root with interposition of a piece of autologous pericardium, and the coronary buttons were connected to the homograft. The aortomitral homograft was connected to the left atrial dome with the donor's dome of left atrial wall, and the interatrial septum and right atrium were closed (Figures 4-6). The heart was weaned successfully from cardiopulmonary bypass in sinus rhythm. The total cardiopulmonary bypass time was 205 minutes, and the total crossclamp time was 182 minutes. Hemostasis was achieved, and chest tubes were placed. Atrial and ventricular temporary pacing wires were placed. The patient was transferred to the intensive care unit in stable condition.

An intraoperative transesophageal echocardiogram showed that the aortomitral homograft was well seated and functioned normally as a native AV and MV unit with normal left and right ventricular functions. There was no aortic regurgitation found, but trivial central mitral regurgitation was seen. The extent of opening and closing of the MV leaflets was similar to that of a native valve. There were neither restriction, abnormal movement, nor increased gradient across the MV, even at high systemic blood pressure (Figure 7).

The patient stayed 1 night in the intensive care unit and was extubated after 18 hours without any cardiac or respiratory support. His chest tubes and pulmonary arterial catheter were discontinued. He was transferred to the ward on his first postoperative day, where atrial fibrillation developed; he underwent direct current cardioversion and remained in sinus rhythm till discharge. The rest of the patient's postoperative stay was uneventful, and he was discharged to home on the 7 th postoperative day.

\section{DISCUSSION}

The idea of using allograft tissue for valve replacement started in the early days of cardiac surgery. Left heart 


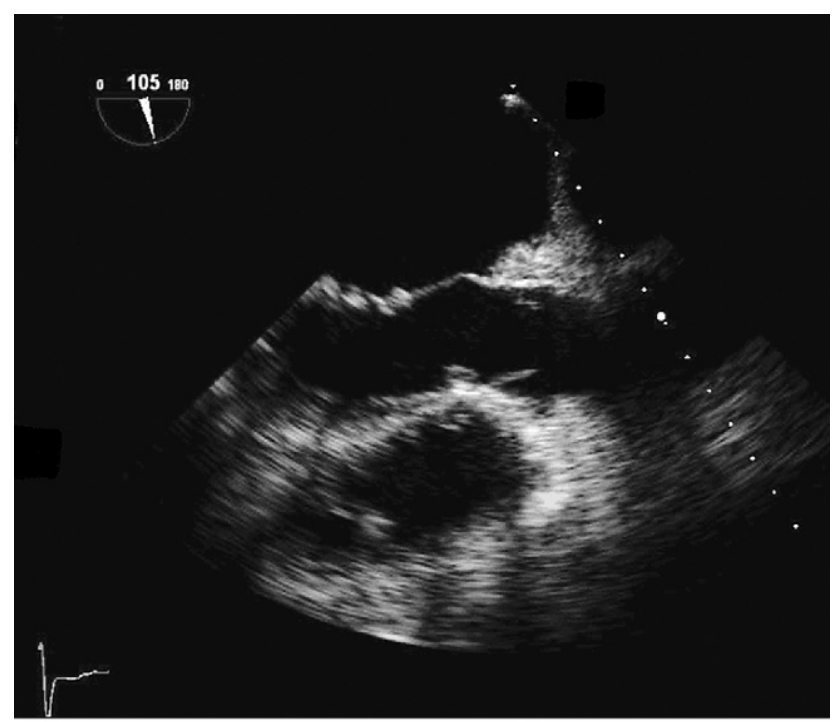

A

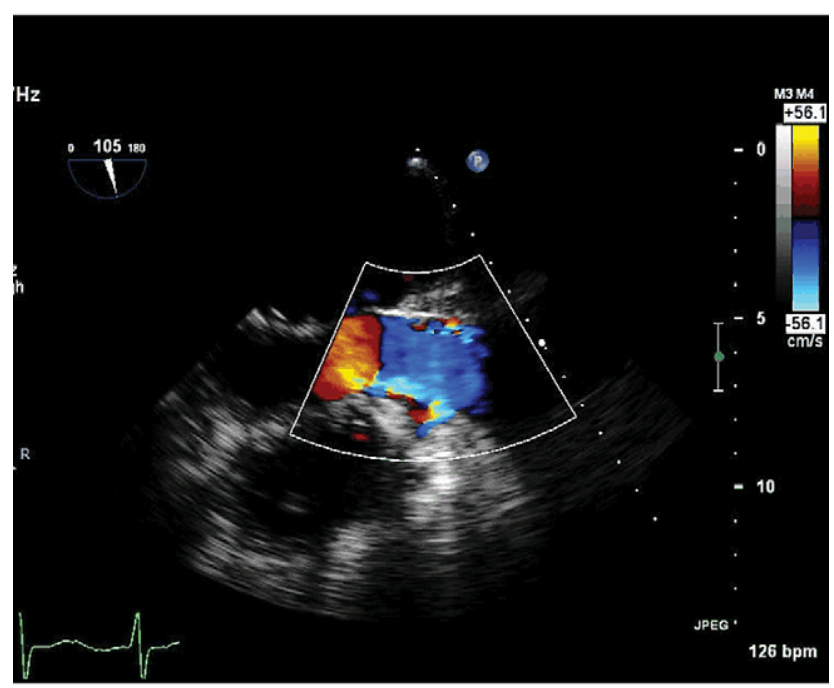

B

FIGURE 7. Postoperative transesophageal echocardiogram showing position (A) and function (B) of homograft.

valves, MV and AV, attracted surgeons' efforts, leading to success in using the pulmonary autograft in the Ross I operation in the aortic position and less success with the same pulmonary autograft in the mitral position in the Ross II operation. At that early point in time, it became clear that the AV apparatus-comprising cusps, commissures, sinuses of Valsalva, sinotubular junction, and coronary ostia-could be mimicked by pulmonary autografts or aortic homografts, which have become the standard of surgical treatment for AV endocarditis. The MV apparatus - comprising papillary muscles, chordae tendineae, anterior and posterior leaflets, and commissures - could not, however, be mimicked by the individually tailored pulmonary autograft or mitral homograft.
The first serious attempt at mitral homograft placement was performed by Senning in 1965; it later failed, with the patient requiring MV rereplacment 3 years later. The technique, created by Acar and described originally by Ali and colleagues, ${ }^{2}$ involved grafting the donor's entire MV with the subvalvular apparatus by anastomosing the donor's papillary muscle tips side to side to the native papillary muscles. This was followed by anastomosing the donor's MV to the native annulus and reinforcing the repair with an annuloplasty ring. The sizing of the MV was done by preoperative echocardiographic measurement of the height of the anterior leaflet. The group saw early dysfunction as a result of mismatch in size when they used the height of anterior leaflet as a reference size indicator. As a result of the work of Ali and colleagues, ${ }^{2}$ we realize now the following important points: (1) The sizing would be better done after surgical exposure with the MV prosthetic sizers. (2) The annuloplasty ring was vital in stabilizing the replacement and absorbing shear stresses on the homograft. (3) Attempts to anastomose the papillary muscles were not successful; despite the fact that in their experience no rupture happened, the muscles underwent fibrosis, thickening, and calcification, leading to fusion and retraction in some cases.

Recently, Acar's technique inspired two more French groups to progress to use aortomitral homograft address the problem of double valve endocarditis. Obadia and colleagues $^{3}$ and Chocron and colleagues, ${ }^{4}$ separately used the monobloc aortomitral graft in 5 and 2 patients, respectively. They used Acar's technique for the MV homograft part, including the papillary muscle anastomosis and the ring, an approach that Acar ${ }^{5}$ rightly advised against, stating a preference for two separate MV and AV homografts because of the inherent technical challenges in and inconclusive success of the MV homograft technique. Obadia and colleagues in return argued that the challenge they were attempting to address with this technique was the restoration of the IFB after extensive resection for abscess or fistula in the context of endocarditis, in which case a double homograft procedure is not a surgical option.

Radical resection of all infected tissue is the principle that is adopted by cardiac surgeons in treating endocarditis to avoid recurrence, sepsis, embolism, and reoperation with high mortality. This would, however, occasionally lead to resection of the IFB and consequently to disruption of the fibrous skeleton of the heart, creating a tissue defect that patching with bovine pericardium or Dacron polyester fabric could not repair satisfactorily. ${ }^{1}$ We therefore suggest this new surgical technique to provide this advantage of incorporating a tissue of almost the same quality of the resected native tissue with the quality of resistance to infection but with the preservation of the invaluable MV subvalvular apparatus. In this report, we have described our technique in which we preserved the posterior leaflet, because it was clear of disease. The technique can be extended to include the posterior 
leaflet of the MV annulus in the same manner as we did the anterior leaflet in this operation.

Our main approach to double valve endocarditis at present is AV homograft with MV repair or MV replacement with a bioprosthesis. There has always, however, been a challenge in IFB reconstruction. This new technique, despite being described here in a case of severe double valve endocarditis, is likely to serve in many other cases in which IFB reconstruction is required for reoperations or cases of extensive calcification at the base of the heart.

\section{References}

1. De Oliveira N, David T, Armstrong S, Ivanov J. Aortic and mitral valve replacement with reconstruction of the intervalvular fibrous body: an analysis of clinical outcomes. J Thorac Cardiovasc Surg. 2005;129:286-90.

2. Ali M, Iung B, Lansac E, Bruneval P, Acar C. Homograft replacement of the mitral valve: eight-year results. $J$ Thorac Cardiovasc Surg. 2004;128:529-34.

3. Obadia J, Hénaine R, Bergerot C, Ginon I, Nataf P, Chavanis N, et al. Monobloc aorto-mitral homograft or mechanical valve replacement: a new surgical option for extensive bivalvular endocarditis. J Thorac Cardiovasc Surg. 2006;131:243-5.

4. Chocron S, Buklas D, Taberlet C, Kaili D, Falcoz P, Etievent J. Monobloc aortomitral homograft: report of two cases. Ann Thorac Surg. 2007;84:e14-6.

5. Acar C. Monobloc or separate aortic and mitral homografts? J Thorac Cardiovasc Surg. 2006;132:442-3.

\title{
Complex diaphragm reconstruction using dermal collagen matrix after multivisceral resection of retroperitoneal sarcoma
}

\author{
Nicholas J. Harms, MD, ${ }^{a}$ Sima Naderi, MD, ${ }^{\mathrm{b}}$ Dariusz Borys, MD, ${ }^{\mathrm{c}}$ Richard J. Bold, MD, ${ }^{\mathrm{a}}$ and \\ Robert J. Canter, MD, ${ }^{\text {a }}$ Sacramento, Calif
}

Successful en bloc resection of retroperitoneal sarcomas may require contiguous organ resection, including the diaphragm. Tension-free, primary repair of the diaphragm is not always technically possible when a large defect is created. Standard reconstruction of complex diaphragmatic defects involves implantation of polytetrafluoroethylene mesh (Gore-Tex; WL Gore and Associates, Newark, Del). However, in the setting of visceral organ resection such as colon or pancreas, implantation of prosthetic mesh may be contraindicated because of concerns of postoperative infection. We report successful implantation of acellular dermal matrix (AlloDerm; LifeCell Corp, Branchburg, $\mathrm{NJ}$ ) to repair complex diaphragmatic defects in 2 patients after multivisceral resection of retroperitoneal sarcomas.

\section{CLINICAL SUMMARY}

A 72-year-old woman presented with an approximately $32-\mathrm{cm}$ recurrent left-sided retroperitoneal myxoid liposarcoma. Cross-sectional imaging suggested involvement of

\footnotetext{
From the Division of Surgical Oncology, ${ }^{\mathrm{a}}$ Department of Radiology, ${ }^{\mathrm{b}}$ and Department of Pathology and Laboratory Medicine, ${ }^{\mathrm{c}}$ University of California at Davis Cancer Center, Sacramento, Calif.

Disclosures: None.

Received for publication July 2, 2009; revisions received July 2, 2009; accepted for publication July 9, 2009; available ahead of print Oct 26, 2009.

Address for reprints: Robert J. Canter, MD, Division of Surgical Oncology, Suite 3010, UC Davis Cancer Center, 4501 X Street, Sacramento, CA 95817 (E-mail: Robert.canter@ucdmc.ucdavis.edu).

J Thorac Cardiovasc Surg 2010;139:1081-3

$0022-5223 / \$ 36.00$

Copyright (C) 2010 by The American Association for Thoracic Surgery

doi:10.1016/j.jtcvs.2009.07.077
}

the distal pancreas, spleen, descending colon, and left hemidiaphragm (Figure 1, A). Staging studies were consistent with localized disease.

Resection of this large, recurrent sarcoma was performed with concurrent left hemicolectomy, distal pancreatectomy, splenectomy, partial psoas muscle, and left hemidiaphragm resection. An approximate $120-\mathrm{cm}^{2}$ defect was created in the diaphragm, extending from the posterior portion of the central tendon to the posterolateral rib cage. Given the size of the defect, a tension-free, primary repair was not technically possible. In the setting of concomitant intestinal and pancreatic resections, implantation of prosthetic mesh was thought to be contraindicated because of the risk of mesh contamination.

Diaphragmatic reconstruction was accomplished with AlloDerm using interrupted 0-0 Prolene sutures to anchor the graft to the rib periosteum posterolaterally, to the left crus medially, and to the central tendon anteriorly (Figure 2).

A 68 -year-old man presented with a $12-\mathrm{cm}$ left retroperitoneal mass that proved to be a renal angiosarcoma (Figure 1, $B)$. At operation, the tumor was found to involve the tail of the pancreas, the spleen, and the diaphragm, necessitating a multivisceral en bloc resection. Resection of a portion of the left hemidiaphragm created an approximately $45-\mathrm{cm}^{2}$ triangular defect, extending laterally and anteriorly from the left crus. Although a portion of the defect was repaired primarily, a complete, tension-free repair was not technically possible. A 3- $\times 7$-cm piece of AlloDerm was used to repair the posterior-lateral defect using interrupted 0-0 Prolene sutures. 